\title{
ANALISIS PENGARUH MOTIVASI DAN STRATEGI PENGELOLAAN TERHADAP OPERASIONAL HOMESTAY DIKABUPATEN KARO
}

\author{
Muhammad Halfi Indra Syahputra, e-mail : halfimedan@gmail.com \\ Politeknik Pariwisata Medan
}

\begin{abstract}
Abstrak
Tujuan pada penelitian ini yaitu untuk mengetahui dan menganalisa pengaruh dari motivasi karyawan terhadap stategi dari operasional homestay dan ability kerja dari karyawan.Penelitian ini menggunakan pendekatan kuantitatif yaitu dengan menggunakan kuisioner.Dan untuk objek dilakukannya pnelitian terdapat di Homestay Kabupaten Karo.Pada pnelitian ini menggunakan metode kuantitatif yaitu dengan mnggunakan analisa regrsi linier berganda dngan uji T, uji F. dan untuk hasil dari penelitian ini secara parsial trdapat beberapa pengaruh signifikan yaitu motivasi kerja pada karyawan dan ability kerja yang terdapat pada karyawan mempunyai pengaruh signifikan terhadap strategi dari pengelolaan homestay di Kabupatn Karo.
\end{abstract}

\section{PENDAHULUAN}

Persaingan bisnis di Indonesia merupakan salah satu yang perlu diprhatikan,terlebih dngan pesatnya perkembangan ekonomi dari globalisasi yang membuat persaingan antara ekonomi dari pengusaha local dengan pengusaha asing. Dengan efek dari globalisasi tersebut memberikan pengaruh terhadap industry jasa yang terdiri dari industry telekomunikasi,perbankan dan perhotelanyang sangat berkembang dengan cepat (Zeithaml,Bit, 2003).

Industri perhotelan yaitu suatu industry yang memadukan antara produk dan layanan.Dimana untuk untuk produk yang dihasilkan dari industry perhotelan diantaranya desaininterior,restaurant yang menydiakan makanan dan minuman yang dapat dijual. Dan untuk layanan yang dijual yaitu keterampilan dari staff karyawan hotel yang memiliki keahlihan baik dari memasak dan melayani dan juga layanan dalam keramah-tamahan.
Terdapat beberapa hal yang harus diperhatikan untuk perkembangan perhotelan yaitu dengan memperhatikan dan memberikan kualitas dan pelayanan yang trbaik untuk para tamu agar para tamu puas terhadap layanan dari hotel tersebut.dalam persaingan bisnis,layanan suatu hal yang perlu diperhatikan untuk perusahaan yaitu dengan memprhatikan strategi yaitu ketika mereka menjual produk yang sama.layanan yang baik yaitu dengan mengutamakan makanan yang enak.dan sebaiknya untuk hidangan utama yang enak tidak menjamin dalam menyelamatkan layanan yang buruk (Orilio,2005). Selain dari pelayanan yang baik, yang prlu diperhatikan yaitu fasilitas. Dimana fasilitas meruakan salah satu cara untuk menarik konsumen, sebab konsumen zaman sekarang sangatlah kritis dan sangat memperhatikan beberapa hal yang perlu diperhatikan dalam menggunakan uang,sehingga mereka lebih banyak memperhatikan beberapa factor dalam memilih produk dari jasa perhotelan. Dan 
fasilitas menjadi salah satu yang diperhatikan untuk dapat menarik konsumen agar konsumen tidak kecewa dan merasa puas dari layanan produk dan jasa dari perhotelan tersebut.

Kabupaten Karo adalah daerah yang berada di Sumatera Utara yang memiliki potensi untuk melakukan bisnis terkhusus untuk industry perhotelan.Potensi yang terdapat di Kabupaten Karo sangat lah baik dengan lokasi yang strategis dan mudah terjangkau dan juga iklim yang sangat sejuk dan cocok digunakan untuk bisnis perhotelan.

Berdasarkan uraian diatas maka dilakukan penelitian yaitu untuk mngetahui factor atau stratgi yang berpengaruh terhadap jumlah penginapan di hotel.

\section{TINJAUAN PUSTAKA}

Motivasi dan kemampuan merupakan hal yang saling berhubungan. Dimana motivasi yaitu suatu faktor yang harus diprhatikan yaitu dengan mendorong sseorang dngan elakukan aktivitas tertentu, dngan hal itu motivasi dapat diartikan yaitu dnegan pelaku atau seseorang.Motivasi krja adalah salah satu factor yang mempngaruhi perilaku dari sesorang. Dari bberapa penelitian motivasi kerja mempunyai pengaruh yang signifikan dengan kinerja karyawan .menurut Aprilia mengatakan bahwa motivasi kerja sangan berpngaruh signifikan dengan jinerja karyawan di Homestay Kabupaten Karo.

Dan untuk kemampuan (ability)adalah kapasitas individu saat ini untuk melakukan berbagai tugas dari pekerjaan. Dan kemampuan ini juga mempunyai pengaruh signifikan terhadap karyawan.trdapat pada penelitian Ghouzali (2017) yang menyatakan dari hasil penelitian bahwa variable dari kemampuan (ability) kerja memepunyai pengaruh yang signifikan dan dominan dari kinerja pegawai di homestay Kabupaten Karo.

Terdapat tiga kunci utama dalam motivasi , yakni: intensitas, arah dan ketekunan. Terdapat 5 Indikator motivasi menurut Hierarki kebutuhan Abraham H. Maslow yaitu yang pertama ialah Fisiologis dimana kebutuhan akan sandang, pangan, dan kebutuhan jasmani lain nya, kedua ialah Keamanan, Anatar lain kebutuhan akan keselamatan dan perlindungan terhadap kerugian fisik, ketiga yaitu sosial antara lain hubungan persahabatan, komunikasi, kekerabatan, dam rasa memiliki, Keempat ialah penghargaan antara lain mencakup faktor penghormatan diri seperti harga diri, otonomi, prestasi, status di sebuah perusahaan, atau pun dapat berupa pengakuan dan perhatian, yang kelima ialah Aktualisasi diri, merupakan dorongan untuk menjadi seseorang yang sesuai dengan ambisi nya.

Strategi Tingkat Bisnisyaitu startegi alternative yang terdapat pada organisasi yag digunakan untuk berbisnis baik di dunia industry terkhusus di industry perhotelan mmerlupakan suatu strategi yang bertujuan untuk mengatur dari proses dan jalannya bisnis. Strategi alternative dari pilihan organisasi tersebut dapat mebantu untuk bersaing di bidang industry.

\section{METODE PENELITIAN}

Pada penelitian ini menggunakan metode kuantitaif yaitu dengan mnggunakanpendekatan kuantitatif dngan menggumpulkan data melalui kuisiner. Penelitian ini bertujuan untuk mengetahui adanya pengaruh motivasi kerja dan ability kerja terhadap strategi dari operasional 
homestaydi Kabupaten Karo. Dan adapun analisa yang digunakan untuk penelitian ini yaitu menggunakan analisa rgresi linier berganda atau uji $\mathrm{T}$ dan uji $\mathrm{F}$.

\section{HASIL DAN PEMBAHASAN}

\section{Uji Validitas}

fungsi dari uji validitas yaitu untuk megetahui valid atau tidaknya suatu butir pertanyaan yaitu dengam melihat korlasi dari $\mathrm{R}$ hitung yaitu dengan butir pertanyaan. Dimana untuk $\mathrm{R}$ hitung > $\mathrm{R}$ table.Yang dapat dilihat pada Tabel 1 hasil dari uji validitas dari seyiap butir pertanyaan dari $R$ hitung dari variable motivasi, ability dan strategi pengelolaan homestay.

\section{Tabel 1}

Uji Validitas Terhadap

\section{Pertanyaan Variabel Strategi Pengelolaan} Homestay, Motivasi dan Ability

\begin{tabular}{|c|c|c|c|}
\hline$\rho$ & R Hituase & R Tabel & Keterangan \\
\hline SPHI & 0.985 & 0.361 & Valid ( $R$ Hioung $>R$ Tabel) \\
\hline $\mathrm{SPH} 2$ & 0.979 & 0.361 & Valid (R Hioung > R Tabel) \\
\hline $\mathrm{SPH} 3$ & 0.985 & 0.361 & Valid ( $R$ Hitung $>R$ Tabel) \\
\hline $\mathrm{SPH} 4$ & 0.956 & 0.361 & Valid ( $R$ Hitung $>R$ Tabel) \\
\hline SPHS & 0.95 & 0.361 & Valid (R Hitung $>R$ Tabei) \\
\hline SPH6 & 0.985 & 0.361 & Valid ( $R$ Hitung $>R$ Tabel) \\
\hline SPH7 & 0.916 & 0.361 & Valid ( $R$ Hinang $>R$ Tabel) \\
\hline SPH8 & 0.937 & 0.361 & Valid (R Hitung $>\mathbf{R}$ Tabel) \\
\hline SPH9 & 0,901 & 0.361 & Valid ( $R$ Hitung $>\mathbb{R}$ Tabel) \\
\hline SPH10 & 0.966 & 0.361 & Valid (R Hitung $>\mathbb{R}$ Tabel) \\
\hline MOT1 & 0.734 & 0.361 & Valid ( $R$ Hitung $>R$ Tabel) \\
\hline MOT2 & 0.844 & 0.361 & Valid ( $R$ Hitung $>R$ Tabel) \\
\hline MOT3 & 0.982 & 0.361 & Valid (R Hitung $>R$ Tabel) \\
\hline MOT4 & 0.919 & 0.361 & Valid ( $R$ Hitung $>R$ Tabel) \\
\hline MOT5 & 0.934 & 0.361 & Valid (R Minung $>$ R Tabel) \\
\hline MOT6 & 0.964 & 0.361 & Valid ( $R$ Hituing > R Tabel) \\
\hline MOT7 & 0.9077 & 0.361 & Valid (R Hinung $>$ R Tabel) \\
\hline MOT8 & 0.934 & 0361 & Valid ( $R$ Hitung > R Tabel) \\
\hline MOT9 & 0.978 & 0.361 & Valid (R Hitung $>$ R Tabel) \\
\hline MOTIO & 0.934 & 0,361 & Valid ( $R$ Hitung $>$ R Tabel) \\
\hline AB1 & 0.961 & 0.361 & Valid (R Hitung $>R$ Tabel) \\
\hline $\mathrm{AB} 2$ & 0.953 & 0,361 & Valid ( $R$ Hitung > R Tabel) \\
\hline $\mathrm{AB} 3$ & 0.967 & 0.361 & Valid ( $R$ Hitung $>R$ Tabel) \\
\hline $\mathrm{AB} 4$ & 0.911 & 0.361 & Valid (R Hitung > R Tabel) \\
\hline AB5 & 0.9 & 0.361 & Valid ( $R$ Hitung $>R$ Tabel) \\
\hline AB6 & 0.975 & 0.361 & Valid ( $R$ Hitumg $>R$ Tabel) \\
\hline AB? & 0.988 & 0.361 & Valid ( $R$ Hitung $>R$ Tabel) \\
\hline ABS & 0.986 & 0.361 & Valid ( $R$ Hitung $>R$ Tabel) \\
\hline$A B 9$ & 0.949 & 0.361 & Valid (R Hitung $>R$ Tabel) \\
\hline $\mathrm{AB} 10$ & 0944 & 0.361 & Valid ( $R$ Hinumg $>R$ Tabel) \\
\hline
\end{tabular}

Dari table diatas dapat dijelaskan bahwa setiap pertanyaan telah valid yaitu dimana $R$ hitung > R Tabel (0,361).Dan dapat diartikan bahwa keseluruhan dari setiap butir pertanyaan dari variable tersebut telah valid yaitu dngan melakukan uji validitas, sehingga dapat dilanjuti dengan uji selanjutnya.

\section{Uji Reliabilitas}

Tujuan dari uji Reliabilitas untuk mengtahui keriablan data tersebut dimana ui ini merupakan lanjutan uji validitas yaitu dengan memperhatikan nilai Cronbach's Alphaharus lbih bsar dari 0,6. Jika nilai Cronbach's Alpha> dari 0,6 aka data tersbut tlah realiabel. Dan dapat dilanjuti dengan langkah selanjutnya.

\section{Tabel 2}

\section{Uji Reliabilitas}

\begin{tabular}{|l|l|}
\hline Variabel & Cromhach's Alphio \\
\hline Strategi Peogelolanan Homestay (Y) & 0.991 \\
\hline Motivasi (X1) & 0.982 \\
\hline Ability (Xz) & 0.991 \\
\hline
\end{tabular}

Dari table diatas dapat diartikan bahwa nilai dari Cronbach's Alpha setiap variable mmpunyai nilai yang lbih bsar dari 0,6 , sehingga dapat disimpulkan bahwa data realibl dan dapat dilaukan dengan uji berikutnya.

\section{Analisis Statistik Deskriptif}

Pada bagian analisis deskriptif, disajikan distribusi frekuensi dan persentase dari variabel strategi pengelolaan homestay, motivasi dan ability. 
Tabel 3

Distribusi Frekuensi dan Persentase berdasarkan Variabel Strategi Pengelolaan Homestay

\begin{tabular}{|c|c|c|c|c|c|c|c|c|c|c|c|c|}
\hline \multirow{2}{*}{ SIS } & \multicolumn{2}{|c|}{ STS } & \multicolumn{2}{|c|}{ TS } & \multicolumn{2}{|l|}{ KS } & \multicolumn{2}{|l|}{ S } & \multicolumn{2}{|l|}{ SS } & \multicolumn{2}{|c|}{ Total } \\
\hline & $\mathbf{F}$ & $\%$ & $F$ & 3 & F & 3 & F & $\%$ & $F$ & 96 & $\mathrm{~F}$ & $\%$ \\
\hline KAI & 0 & 0 & 6 & 12 & 3 & 6 & 30 & 60 & 11 & 22 & 50 & 100 \\
\hline $\mathrm{KA} 2$ & 1 & 2 & 4 & 8 & 6 & 12 & 26 & 52 & 13 & 26 & 50 & 100 \\
\hline KA3 & 0 & 0 & 6 & 12 & 5 & 10 & 27 & 54 & 12 & 24 & 50 & 100 \\
\hline KA4 & 0 & 9 & 5 & 10 & 9 & 18 & 24 & 48 & 12 & 24 & 50 & 100 \\
\hline KA5 & 1 & 2 & 5 & 10 & 8 & 16 & 24 & 48 & 12 & 24 & 50 & 100 \\
\hline KA6 & 0 & 0 & 3 & 6 & 3 & 6 & 29 & 58 & 15 & 30 & 50 & 100 \\
\hline KA7 & 0 & 0 & 6 & 12 & 3. & 6 & 20 & 40 & 21 & 42 & 50 & 100 \\
\hline KAB & 1 & 2 & $\mathrm{~s}$ & 16 & 3 & 6 & 22 & 44 & 16 & 32 & 50 & 100 \\
\hline KA9 & 0 & 0 & 5 & 10 & 14 & 28 & 25 & 50 & 6 & 12 & 50 & 100 \\
\hline KAlO & 0 & 0 & 6 & 12 & 5 & 10 & 30 & 60 & 9 & 18 & 50 & 100 \\
\hline
\end{tabular}

Berdasarkan Tabel 4.3, untuk pertanyaan ke1 (KA1), terdapat $6(12.00 \%)$ responden menjawab TS, responden menjawab KS sebanyak $3(6.00 \%)$, responden menjawab $S$ sebanyak $30 \quad(60.00 \%)$ dan responden menjawab SS sebanyak 11 (22.00\%). Untuk pertanyaan ke-2 (KA2), terdapat $1(2.00 \%)$ responden menjawab STS, responden menjawab TS sebanyak 4 (8.00\%), responden menjawab KS sebanyak 6 $(12.00 \%)$, responden menjawab $\mathrm{S}$ sebanyak $26(52.00 \%)$ dan responden menjawab SS sebanyak 13 (26.00\%). Untuk pertanyaan ke-3 (KA3), terdapat $6(12.00 \%)$ responden menjawab TS, responden menjawab KS sebanyak 5 (10.00\%), responden menjawab S sebanyak 27 (54.00\%) dan responden menjawab SS sebanyak 12 (24.00\%). Untuk pertanyaan ke-4 (KA4), terdapat 5 (10.00\%) responden menjawab $\mathrm{TS}$, responden menjawab KS sebanyak 9 (18.00\%), responden menjawab $S$ sebanyak 24 $(48.00 \%)$ dan responden menjawab SS sebanyak 12 (24.00\%). Untuk pertanyaan ke-5 (KA5), terdapat $1(2.00 \%)$ responden menjawab STS, responden menjawab TS sebanyak $5(10.00 \%)$, responden menjawab KS sebanyak 8 (16.00\%), responden menjawab S sebanyak 24 (48.00\%) dan responden menjawab SS sebanyak 12 $(24.00 \%)$.
Untuk pertanyaan ke-6 (KA6), terdapat 3 (6.00\%) responden menjawab TS, responden menjawab KS sebanyak 3 (6.00\%), responden menjawab $\mathrm{S}$ sebanyak 29 $(58.00 \%)$ dan responden menjawab SS sebanyak 15 (30.00\%). Untuk pertanyaan ke-7 (KA7), terdapat $6(12.00 \%)$ responden menjawab TS, responden menjawab KS sebanyak $3(6.00 \%)$, responden menjawab $S$ sebanyak $20 \quad(40.00 \%)$ dan responden menjawab SS sebanyak 21 (42.00\%). Untuk pertanyaan ke-8 (KA8), terdapat 1 (2.00\%) responden menjawab STS, responden menjawab TS sebanyak 8 (16.00\%), responden menjawab KS sebanyak 3 (6.00\%), responden menjawab $\mathrm{S}$ sebanyak $22(44.00 \%)$ dan responden menjawab SS sebanyak 16 (32.00\%). Untuk pertanyaan ke-9 (KA9), terdapat $5(10.00 \%)$ responden menjawab TS, responden menjawab KS sebanyak 14 (28.00\%), responden menjawab $\mathrm{S}$ sebanyak $25(50.00 \%)$ dan responden menjawab SS sebanyak 6 (12.00\%). Untuk pertanyaan ke-10 (KA10), terdapat 6 (12.00\%) responden menjawab TS, responden menjawab KS sebanyak 5 $(10.00 \%)$, responden menjawab S sebanyak $30(60.00 \%)$ dan responden menjawab SS sebanyak 9 (18.00\%).

\section{Tabel 4}

\section{Distribusi Frekuensi dan Persentase berdasarkan Variabel Motivasi}

\begin{tabular}{|c|c|c|c|c|c|c|c|c|c|c|c|c|}
\hline \multirow{2}{*}{ STS } & \multicolumn{2}{|c|}{ STS } & \multicolumn{2}{|l|}{ Is } & \multicolumn{2}{|c|}{ KS } & \multicolumn{2}{|l|}{5} & \multicolumn{2}{|l|}{55} & \multicolumn{2}{|c|}{ Total } \\
\hline & $F$ & $\%$ & $F$ & $\%$ & $F$ & $\%$ & F & 94 & $F$ & $9 /$ & $F$ & $\%$ \\
\hline II & I & 2 & 4 & 8 & 5 & 10 & 19 & 38 & 21 & 42 & 50 & 100 \\
\hline 12 & 8 & 16 & 22 & 44 & 7 & 14 & 3 & 6 & 10 & 20 & 50 & 100 \\
\hline 13 & 2 & 4 & 20 & 40 & 14 & 28 & 8 & 16 & 6 & 12 & 50 & 100 \\
\hline 14 & 4 & 8 & 31 & 62 & 5 & 10 & 3 & 6 & 7 & 14 & 50 & 100 \\
\hline IS & 5 & 10 & 30 & 60 & 5 & 10 & 2 & 4 & 8 & 16 & 50 & 100 \\
\hline 16 & 2 & 4 & 28 & 56 & 14 & 28 & 0 & 0 & 6 & 12 & 50 & 100 \\
\hline 17 & 0 & 0 & 10 & 20 & 15 & 30 & 15 & 30 & 10 & 20 & 50 & 100 \\
\hline 18 & 1 & 2 & 6 & 12 & 15 & 30 & 18 & 36 & 10 & 20 & 50 & 100 \\
\hline 19 & 1 & 2 & 10 & 20 & 26 & 52 & 5 & 10 & 8 & 16 & 50 & 100 \\
\hline 110 & 0 & 0 & 10 & 20 & 16 & 32 & 12 & 24 & 12 & 24 & 50 & 100 \\
\hline
\end{tabular}

Berdasarkan Tabel 4.4, untuk pertanyaan ke11 (I1), terdapat $1(2.00 \%)$ responden 
menjawab STS, responden menjawab TS sebanyak 4 (8.00\%), responden menjawab KS sebanyak $5(10.00 \%)$, responden menjawab S sebanyak $19(38.00 \%)$ dan responden menjawab SS sebanyak 21 (42.00\%). Untuk pertanyaan ke-12 (I2), terdapat $8(16.00 \%)$ responden menjawab STS, responden menjawab TS sebanyak 22 (44.00\%), responden menjawab KS sebanyak 7 (14.00\%), responden menjawab S sebanyak $3(6.00 \%)$ dan responden menjawab SS sebanyak 10 (20.00\%). Untuk pertanyaan ke-13 (I3), terdapat $2(4.00 \%)$ responden menjawab STS, responden menjawab TS sebanyak 20 (40.00\%), responden menjawab KS sebanyak 14 (28.00\%), responden menjawab S sebanyak $8(16.00 \%)$ dan responden menjawab SS sebanyak $6(12.00 \%)$. Untuk pertanyaan ke14 (I4), terdapat $4(8.00 \%)$ responden menjawab STS, responden menjawab TS sebanyak 31 (62.00\%), responden menjawab KS sebanyak 5 (10.00\%), responden menjawab S sebanyak $3 \quad(6.00 \%)$ dan responden menjawab SS sebanyak 7 (14.00\%)

Untuk pertanyaan ke-15 (I5), terdapat 5 (10.00\%) responden menjawab STS, responden menjawab TS sebanyak 30 (60.00\%), responden menjawab KS sebanyak 5 (10.00\%), responden menjawab $S$ sebanyak $2(4.00 \%)$ dan responden menjawab SS sebanyak 8 (16.00\%). Untuk pertanyaan ke-16 (I6), terdapat $2(4.00 \%)$ responden menjawab STS, responden menjawab TS sebanyak 28 (56.00\%), responden menjawab KS sebanyak 14 (28.00\%) dan responden menjawab SS sebanyak $6(12.00 \%)$. Untuk pertanyaan ke17 (I7), terdapat $10(20.00 \%)$ responden menjawab TS, responden menjawab KS sebanyak 15 (30.00\%), responden menjawab S sebanyak $15(30.00 \%)$ dan responden menjawab SS sebanyak 10 (20.00\%). Untuk pertanyaan ke-18 (I8), terdapat 1 (2.00\%) responden menjawab STS, responden menjawab TS sebanyak 6 (12.00\%), responden menjawab KS sebanyak 15 $(30.00 \%)$, responden menjawab $\mathrm{S}$ sebanyak $18(36.00 \%)$ dan responden menjawab SS sebanyak $10(20.00 \%)$. Untuk pertanyaan ke-19 (I9), terdapat $1(2.00 \%)$ responden menjawab STS, responden menjawab TS sebanyak 10 (20.00\%), responden menjawab KS sebanyak 26 (52.00\%), responden menjawab S sebanyak $5 \quad(10.00 \%)$ dan responden menjawab SS sebanyak 8 (16.00\%). Untuk pertanyaan ke-20 (I10), terdapat $10(20.00 \%)$ responden menjawab TS, responden menjawab KS sebanyak 16 $(32.00 \%)$, responden menjawab $S$ sebanyak $12(24.00 \%)$ dan responden menjawab SS sebanyak $12(24.00 \%)$

\section{Tabel 5}

Distribusi Frekuensi dan Persentase berdasarkan Variabel Ability

\begin{tabular}{|c|c|c|c|c|c|c|c|c|c|c|c|c|}
\hline \multirow{2}{*}{ STS } & \multicolumn{2}{|c|}{ STS } & \multicolumn{2}{|c|}{ TS } & \multicolumn{2}{|l|}{ KS } & \multicolumn{2}{|l|}{ S } & \multicolumn{2}{|c|}{ SS } & \multicolumn{2}{|c|}{ Total } \\
\hline & F & $\%$ & $\mathrm{~F}$ & $\%$ & F & $\%$ & $F$ & 96 & $\boldsymbol{F}$ & 96 & F & $\%$ \\
\hline FAI & 2 & 4 & 5 & 10 & 33 & $6 \hbar$ & 6 & 12 & 4 & 8 & 50 & 100 \\
\hline FA2 & 0 & 0 & 6 & 12 & 8 & 16 & 27 & 54 & 9 & 18 & 50 & 100 \\
\hline FA3 & 1 & 2 & 7 & 14 & 20 & 40 & 18 & 36 & 4 & 8 & 50 & 100 \\
\hline FA4 & 0 & 0 & 3 & 6 & 8 & 16 & 30 & 60 & 9 & 18 & 50 & 100 \\
\hline FA5 & 0 & 0 & 8 & 16 & 17 & 34 & 20 & 40 & 5 & 10 & 50 & 100 \\
\hline FA6 & 1 & 2 & 7 & 14 & 4 & 8 & 32 & 64 & 6 & 12 & 50 & 100 \\
\hline FA? & 0 & 0 & 6 & 12 & 7 & 14 & 31 & 62 & 6 & 12 & 50 & 100 \\
\hline FA8 & 0 & 0 & 5 & 10 & 11 & 22 & 28 & 56 & 6 & 12 & 50 & 100 \\
\hline FA9 & 1 & 2 & 8 & 16 & 14 & 28 & 22 & 44 & 5 & 10 & 50 & 100 \\
\hline FAlO & 0 & 0 & 4 & 8 & 22 & 44 & 18 & 36 & 6 & 12 & 50 & 100 \\
\hline
\end{tabular}

Berdasarkan Tabel 4.5, untuk pertanyaan ke21 (FA1), terdapat $2(4.00 \%)$ responden menjawab STS, responden menjawab TS sebanyak 5 (10.00\%), responden menjawab KS sebanyak 33 (66.00\%), responden menjawab S sebanyak $6 \quad(12.00 \%)$ dan responden menjawab SS sebanyak 4 $(8.00 \%)$. Untuk pertanyaan ke-22 (FA2), terdapat $6(12.00 \%)$ responden menjawab $\mathrm{TS}$, responden menjawab KS sebanyak 8 
(16.00\%), responden menjawab S sebanyak $27(54.00 \%)$ dan responden menjawab SS sebanyak $9(18.00 \%)$. Untuk pertanyaan ke23 (FA3), terdapat $1(2.00 \%)$ responden menjawab STS, responden menjawab TS sebanyak 7 (14.00\%), responden menjawab KS sebanyak $20 \quad(40.00 \%)$, responden menjawab S sebanyak 18 (36.00\%) dan responden menjawab SS sebanyak 4 $(8.00 \%)$. Untuk pertanyaan ke-24 (FA4), terdapat $3(6.00 \%)$ responden menjawab TS, responden menjawab KS sebanyak 8 (16.00\%), responden menjawab $S$ sebanyak $30(60.00 \%)$ dan responden menjawab SS sebanyak 9 (18.00\%). Untuk pertanyaan ke25 (FA5), terdapat $8(16.00 \%)$ responden menjawab TS, responden menjawab KS sebanyak 17 (34.00\%), responden menjawab $\mathrm{S}$ sebanyak $20(40.00 \%)$ dan responden menjawab SS sebanyak 5 (10.00\%).

Untuk pertanyaan ke-26 (FA6), terdapat 1 $(2.00 \%)$ responden menjawab STS, responden menjawab TS sebanyak 7 (14.00\%), responden menjawab KS sebanyak $4(8.00 \%)$, responden menjawab $S$ sebanyak $32 \quad(64.00 \%)$ dan responden menjawab SS sebanyak 6 (12.00\%). Untuk pertanyaan ke-27 (FA7), terdapat $6(12.00 \%)$ responden menjawab $\mathrm{TS}$, responden menjawab KS sebanyak 7 (14.00\%), responden menjawab $\mathrm{S}$ sebanyak 31 $(62.00 \%)$ dan responden menjawab SS sebanyak 6 (12.00\%). Untuk pertanyaan ke28 (FA8), terdapat $5(10.00 \%)$ responden menjawab TS, responden menjawab KS sebanyak $11(22.00 \%)$, responden menjawab $\mathrm{S}$ sebanyak 28 (56.00\%) dan responden menjawab SS sebanyak 6 (12.00\%). Untuk pertanyaan ke-29 (FA9), terdapat $1(2.00 \%)$ responden menjawab STS, responden menjawab TS sebanyak 8 (16.00\%), responden menjawab KS sebanyak 14 (28.00\%), responden menjawab S sebanyak $22(44.00 \%)$ dan responden menjawab SS sebanyak 5 (10.00\%). Untuk pertanyaan ke30 (FA10), terdapat $4(8.00 \%)$ responden menjawab TS, responden menjawab KS sebanyak 22 (44.00\%), responden menjawab $\mathrm{S}$ sebanyak $18(36.00 \%)$ dan responden menjawab SS sebanyak $6(12.00 \%)$.

\section{Uji Asumsi Klasik}

\section{Uji Normalitas}

Uji normalitas bertujuan untuk menguji apakah dalam model regresi, variabel pengganggu atau residual memiliki distribusi normal.Uji $t$ dan $F$ mengasumsikan bahwa nilai residual mengikuti distribusi normal.Dalam penelitian ini, uji normalitas terhadap residual dengan menggunakan uji Kolmogorov-Smirnov. Tingkat signifikansi yang digunakan $\alpha=0,05$. Dasar pengambilan keputusan adalah melihat angka probabilitas $p$, dengan ketentuan sebagai berikut.

Jika nilai probabilitas $p \geq 0,05$, maka asumsi normalitas terpenuhi.

Jika probabilitas < 0,05, maka asumsi normalitas tidak terpenuhi.

\section{Tabel 4.6}

Uji Normalitas

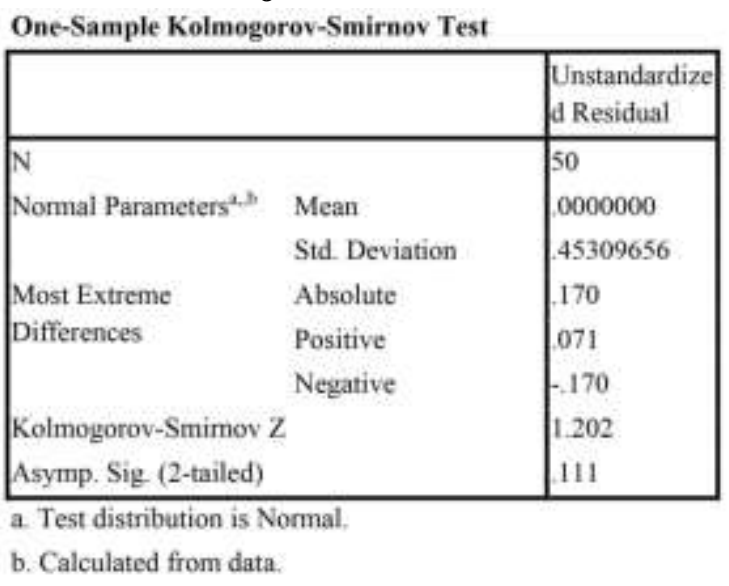


Perhatikan bahwa berdasarkan Tabel 4.6, diketahui nilai probabilitas $\mathrm{p}$ atau Asymp.Sig. (2-tailed) sebesar 0,111. Karena nilai probabilitas p, yakni 0,111 , lebih besar dibandingkan tingkat signifikansi, yakni 0,05 . Hal ini berarti data berdistribusi normal.

\subsubsection{Uji Multikolinearitas}

Untuk memeriksa apakah terjadi multikolinearitas atau tidak dapat dilihat dari nilai variance inflation factor (VIF). Nilai VIF yang lebih dari 10 diindikasi suatu variabel bebas terjadi multikolinearitas (Ghozali, 2013).

\section{Tabel 4.7 Uji Multikolinearitas}

\begin{tabular}{|l|l|l|}
\hline \multirow{2}{*}{ Model } & \multicolumn{2}{|l|}{$\begin{array}{l}\text { Collinearity } \\
\text { Statistics }\end{array}$} \\
\cline { 2 - 3 } & Tolerance & VIF \\
\hline 1 (Constant) & & \\
Motivasi & .865 & 1.156 \\
(X1) & & \\
Ability & .865 & 1.156 \\
$(\mathrm{X} 2)$ & & \\
\hline
\end{tabular}

Perhatikan bahwa berdasarkan Tabel 4.7, nilai VIF dari motivasi adalah 1,156 dan nilai VIF dari ability adalah 1,156.Dikarenakan seluruh nilai VIF $<10$, maka disimpulkan tidak terjadi multikolinearitas.

\subsubsection{Uji Heteroskedastisitas}

Deteksi ada tidaknya heteroskedastisitas dapat dilakukan dengan melihat ada tidaknya pola tertentu pada grafik scatter plot antara SRESID pada sumbu Y, dan ZPRED pada sumbu X.(Ghozali, 2013).Ghozali (2013) menyatakan dasar analisis adalah jika ada pola tertentu, seperti titik-titik yang ada membentuk pola tertentu yang teratur, maka mengindikasikan telah terjadi heteroskedastisitas.Jika tidak ada pola yang jelas, serta titik-titik menyebar di atas dan di bawah angka 0 pada sumbu $\mathrm{Y}$, maka tidak terjadi heteroskedastisitas.

\section{KESIMPULAN DAN SARAN}

\section{Kesimpulan}

1. Dari hasil perhitungan terhadap tiap item pertanyaan dari masing-masing variable didapatkan data bahwa angka pada item 1 sampai 10 pada instrument pertanyaan "motivasi" menunjukkan angka terkecil 0,734 sedangkan angka terbesar 0,982 .

2. Sedangkan, hasil pengujian pengujian item pertanyaan 1 sampai 10 untuk instrument "strategi pengelola homestay" memperoleh angka terkecil sebesar 0,901 dan angka yang terbesar sebesar 0,982. Dan untuk instrument "ability" dapat diperoleh angka terbesar sebesar 0,988 dan angka terkecil sebesar 0,9 .

3. Dari uji pengaruh simultan dengan uji $\mathrm{F}$ dapat diperoleh i nilai $\mathrm{F}$ hitung 38,811 dan nilai Sig. adalah 0,000. Diketahui nilai $\mathrm{F}$ hitung 38,811> F tabel 3,09 dan nilai Sig adalah $0,000<0,05$, maka motivasi dan ability secara bersamasama atau simultan berpengaruh signifikan terhadap strategi pengelolaan homestay

\section{Saran}

1. Agar selalu meningkatkan motivasi dalam bekerja dalam mengelola startegi homestay di Kabupaten 
Karo,dan dapat meningkatkan motivasi dari manager di homestay dengan melakukan beberapa upaya yaitu dengan memmfasilitasi seluruh perlengkapan dari homestay dan memberikan pengetahuan atau papangan mengenai homestay

2. Untuk dapat meningkatkan fasilitas sarana dan prasarana yang ada di dalam homestay agar proses kegiatan dapat berjalan dengan baik. Dan memberikan pemahaman mengenai pengetahuan terkait teknologi atau media untuk dapat bersaing dengan yang lainnya

3. Agar penelitian ini dapat dilakukan lebih lanjut lagi dan perlu dilakukan pengembangan untuk mendapatkan hasil yang diharapkan dan agar penelitian ini lebih baik lagi kedepannya.

\section{DAFTAR PUSTAKA}

Alexander, Mattew dkk . 2014. Reassesing The Core of Hospitality Management Education: The Continuing Importance of Training Restaurants. Jurnal of Hospitality,Leisure, Sport and Tourism Education. Vol 8,No1. www.heacademy.ac.uk/johlste

Asker, S., Boronyak, L., Carrard, N., and Paddon, M., 2010. Effective Community JUMPA Volume 2 Nomor 2 Januari 2016

Häusler, Nicole \& Strasdas, Wolfgang , 2003, Training Manual for Community-Based Tourism. Zschortau.
H. Lovelock, Christopher dan K. Wright, Lauren, 2007. Manajemen Pemasaran Jasa, Penerbit PT. Indeks, Jakarta.

Hermawan Kertajaya. 2002. Marketing Plus 2000; Siasat Memenangkan Persaingan Global, Jakarta: Granedia Pustaka Utama.

Husein Umar, Strategic Management in Action, Jakarta: PT Gramedia Pustaka Utama, 2001

Lili Adi Wibowo. 2011. Handout Metodologi Penelitian.

Kepmen Parekraf No. 9 Tahun 2014 tentang Pondok Wisata atau Homestay

Kim , Youngmi dkk. 2011. Hotel Employees' Competecies and Qualifications Required According to Hotel Divisions. Jurnal Tourism, Hospitality andCulinary Arts. Vol 3 issue 2, 1-18, 2011

Kotler, Philip, Kevin Lane Keller. 2012. Marketing Management 14th Edition. New Jersey : Prentince Hall.

Pendit, Nyoman,1994. Ilmu Pariwisata.P.N Penerbit Pradnjaparamita, Jakarta

Suansri, Potjana, 2003, Community Based Tourism Hand Book, Thailand : Rest Project

Sugiyono, 2012. Metode Penelitian Kuantitatif Kualitatif dan R\&D. Alfabeta : Bandung.

Tewari, Jatashankar R (2009). Hotel Front office.Oxford University Press. India Yoeti, Oka A , 1995. Pengantar Ilmu Pariwisata, Angkasa.Bandung. 


\begin{tabular}{|l|l|l|l|l|}
\hline Jurnal Akomodasi Agung & Vol -VI & NO.2 & Oktober 2020 & ISSN 2503-2119 \\
\hline
\end{tabular}

\section{Website:}

Fathiaauli,2015. Motivasi Kerja Terhadap Karyawan 08-09 diunduh pada tanggal 28 April $2020 \quad$ dari http://digilib.polban.ac.id/files/disk1/1 61/jbptppolban-gdl-fathiaauli-8015-3bab2--9.pdf

Pratiwi NE, 2018.Pengaruh Dimensi Kompetensi Terhadap Kinerja Pegawai Pada Dinas Tenaga Kerja Kota Cimahi 40-41 diunduh pada tanggal 28 April 2020 darihttp://repository.unpas.ac.id/330 43/3/BAB2\%5B1\%5D.pdf

Angky, F. \& Deden, AW. 2017. Analisis Pengaruh Kemampuan dan Motivasi Kerja Terhadap Kinerja Pegawai pada PT. Lakumas Rancaekek Bandung 2930.

file:///C:/Users/ASUS/Downloads/202Article\%20Text-586-1-1020170418.pdf 